\title{
RESISTÊNCIA DE GRÃOS DE FEIJÃO (Phaseolus vulgaris L.) AO FLUXO DE AR E DETERMINAÇÃO DE PROPRIEDADES FÍSICAS EM RELAÇÃO AO TEOR DE UMIDADE
}

\author{
Indira Tainá de Oliveira Santos ${ }^{1}$; Abraão Brito Peixotoº \\ 1. Bolsista PROBIC/UEFS, Graduando em Engenharia de Alimentos, Universidade Estadual de Feira de Santana, e-mail: \\ indiira.taina@hotmail.com \\ 2. Orientador, Departamento de Tecnologia, Universidade Estadual de Feira de Santana, e-mail: abraaopeixoto@uefs.br
}

PALAVRAS-CHAVE: umidade; secagem; armazenamento.

\section{INTRODUÇÃO}

O Brasil configura-se como o maior produtor mundial de feijão-comum do tipo carioca pertencente à espécie (Phaseolus vulgaris L.) (FAO, 2013; SANTOS, 2014). Ainda que a baixa fertilidade dos solos, doenças e estiagem que desencadeiam em forte escassez sejam fatores que limitam efetivamente o potencial produtivo da cultura, são os principais problemas enfrentados nas regiões subtropicais e tropicais. A temperatura e as chuvas são elementos climáticos que mais influenciam na produção de feijão, prejudicando o florescimento e a frutificação do feijoeiro (MAPA, 2010). Podemos destacar dentro destes aspectos, o município de Irecê no semiárido baiano, no qual a região econômica se caracteriza como predominantemente agrícola, tendo prevalecido por muitas décadas a monocultura do feijão, do tipo carioca (Phaseolus vulgaris L.). Porém, no início da década de 1990 inicia-se uma grande crise na região, principalmente no setor da produção de feijão. A EMBRAPA (Empresa Brasileira de Pesquisa Agropecuária) afirma que o solo da região além de pouco profundo, possui, atualmente, baixa retenção de umidade, uma pobre atividade microbiana e um reduzido desenvolvimento das raízes das plantas, afetando assim a produtividade (Embrapa, 1993), porém se destacando ainda como produtor de feijão do tipo carioca, na região do semiárido baiano.

Considerando a necessidade de melhorias tecnológicas no processamento da póscolheita, objetivando produtos de maior qualidade, o conhecimento das propriedades físicas, térmicas e fluidodinâmicas de produtos agrícolas é de total importância na otimização dos processos industriais, projeto e dimensionamento de equipamentos utilizados nas operações de colheita e pós-colheita e para uma correta conservação de produtos agrícolas, contribuindo também para minimizar os custos de produção para maior competitividade e melhoria da 
qualidade final do produto processado. (RESENDE et al., 2008; SANTOS, 2014). Para que haja um armazenamento eficiente de grãos agrícolas a granel, é necessário o controle de aeração após a operação de secagem. Com vistas à longevidade do armazenamento e manutenção da qualidade dos grãos, a aeração pós-secagem reduz a atividade biológica da biota nativa e evita a deterioração do produto estocado. Durante essa operação, um fluxo de ar forçado permeia a massa de grãos e escoa em canais intergranulares, o que causa resistência ao fluxo concomitantemente à perda de carga, também conhecida como perda de pressão ou pressão estática a ser vencida. Tal resistência ao fluxo de ar em leitos fluidizados depende de diversos fatores, tais como: velocidade superficial, profundidade do leito de grãos, presença de impurezas no produto, tamanho, forma, umidade, porosidade e rugosidade do produto. $\mathrm{O}$ preenchimento da coluna de grãos pode seguir uma metodologia interferente na sua compactação, direção do fluxo de ar e resistência do produto à passagem de um fluxo de ar. Nos cálculos da resistência causada pela massa de grãos ao fluxo de ar, os principais parâmetros envolvidos são a porosidade e as massas específicas, real e aparente, diretamente influenciadas pela presença de impurezas no produto e seu teor de umidade.

Tendo em vista os aspectos mencionados, este trabalho teve por objetivo geral a determinação das propriedades relacionadas com a transferência de calor em massa de grãos de feijão (Phaseolus vulgaris L.) em função do teor de água das amostras e com a resistência dos grãos ao fluxo de ar com velocidade superficial controlada. Especificamente, objetivou-se determinar as massas específicas, real e aparente, o teor de umidade, a porosidade do leito de grãos, a condutividade térmica, a difusividade e o calor específico da massa de grãos em variadas percentagens de conteúdo de água, ressaltando que foi possível obter resultados apenas das massas reais dos grãos e teor de umidade das amostras.

\section{MATERIAL E MÉTODOS OU METODOLOGIA (ou equivalente)}

O presente trabalho foi realizado no Laboratório de Operações Unitárias da Universidade Estadual de Feira de Santana e seguiu a proposta de Andrade et al. (2004) com algumas adaptações necessárias. Foram utilizados grãos de feijão (Phaseolus vulgaris L.), provenientes de município do semiárido baiano. Antes de iniciar o estudo das propriedades térmicas, o teor de água e a massa específica das amostras de grãos de feijão foram determinados. Para tal, foram feitas amostragens de quatro lotes de grãos com $15 \mathrm{~kg}$ cada, obtendo amostras-mães que continham $5 \mathrm{~kg}$ de grãos de cada lote. 
Antes de cada experimento realizado para a determinação das propriedades térmicas das amostras de feijão, o produto, acondicionado em sacos plásticos vedados, foi submetido á câmara B.O.D. $\left(20^{\circ} \mathrm{C}\right)$, a fim de evitar absorção de umidade e interferência nas análises.

Foram investigadas amostras com três teores de umidade $(15,5 ; 16,0 ; 16,3 \%)$, obtidas por meio de secagens em secadores de ar de fluxo forçado com velocidade de 3,4 m/s, a 40 e $60^{\circ} \mathrm{C}$. O teor de água dos grãos, em todas as etapas envolvidas no trabalho, foi determinado pelo medidor de umidade de grãos (conforme figura 1 ), $25 \pm 3^{\circ} \mathrm{C}$, com três repetições, de acordo com as Regras para Análise de Sementes (BRASIL, 1992). O peso real dos grãos de feijão foram obtidos antes e após os períodos de secagem dos grãos, em balança semianalítica.

Após a conclusão da montagem e desenvolvimento do hardware, serão realizados os outros experimentos, atingindo os objetivos propostos pelo plano de trabalho. Portanto, os objetivos serão cumpridos e apresentados no SEMIC, caso seja executado em tempo hábil para preparo do material para apresentação.

\section{RESULTADOS E/OU DISCUSSÃO (ou Análise e discussão dos resultados)}

Segundo o que rege a Agência Nacional de Vigilância Sanitária (ANVISA), os grãos de feijão não podem ultrapassar $16 \%$ de teor de umidade. Após análise de umidade do primeiro lote de grãos, verificou-se que o teor de umidade apresentava-se acima do nível permitido pela legislação vigente, os lotes apresentavam teor de umidade entre 15,5 e 16,3\%, inicialmente. A partir de então, foram feitas secagens das amostras de trabalho dos outros lotes de grãos, em secador de fluxo forçado de ar em temperaturas testadas, com velocidade de ar $3,4 \mathrm{~m} / \mathrm{s}$, a fim de reduzir o teor de umidade, adequando-o á legislação vigente, e observar a relação entre umidade e temperatura, a fim de verificar melhor temperatura e respectivo teor de umidade para secagem e armazenamento de grãos de feijão, sem que prejudicasse a qualidade dos mesmos. Assim, foi possível obter teores de umidade entre 15,2 a $15,6 \%$, na faixa de temperatura ideal escolhida 60 a $65^{\circ} \mathrm{C}$.

Os pesos reais das amostras foram avaliados antes e após cada etapa de secagem realizada.

Os valores obtidos experimentalmente para o peso real de grãos de feijão a diferentes teores de água são apresentados na tabela 1, junto aos valores obtidos para a umidade dos grãos de feijão, e tempos utilizados para o cálculo dos respectivos valores da grandeza, seguidos dos desvios padrão das médias utilizadas. 
Tabela 1 - Relação entre temperatura e umidade

\begin{tabular}{ccccc}
\hline & Inicial & $\mathbf{4 0}^{\mathbf{}} \mathbf{C} / 30$ min & $\mathbf{6 0}^{\mathbf{}} \mathbf{C} / 50 m i n$ & $\mathbf{6 5}^{\circ} \mathbf{C} / 80 m i n$ \\
\hline Massa $(\mathbf{g})$ & $209,38 \pm 4,70$ & $206,21 \pm 2,67$ & $200,3 \pm 3,81$ & $199,14 \pm 3,73$ \\
Teor de umidade $(\boldsymbol{\%})$ & $16,30 \pm 0,40$ & $15,93 \pm 0,17$ & $15,69 \pm 0,33$ & $15,23 \pm 0,06$ \\
\hline
\end{tabular}

Fonte: Os autores.

Observa-se que à medida que aumenta o tempo de secagem, os valores da massa real dos grãos de feijão diminuem à medida que o teor de água diminui a partir de evaporação, o que pode ser explicado pela perda de água e alguns nutrientes do grão, por possível desnaturação destes últimos, durante o período de secagem do produto, o que consequentemente favorece a perda de massa do grão, o que pode ser verificado a partir da curva de umidade obtida com estas análises, que pode ser observada através da leitura a partir da direita do gráfico, exposto na figura 4. Os altos valores de desvios padrão observados para a massa dos grãos podem estar relacionados com a diferença de peso entre as amostras de trabalho iniciais, as quais apresentavam cerca de $5,0 \mathrm{~g}$ de diferença, explicado pela necessidade de colocar um peso adequado nas bandejas utilizadas, para que fosse possível a obtenção de resultados coerentes pelo equipamento utilizado para secagem, de modo a cobrir com os grãos toda a área inferior das bandejas. No entanto, os desvios padrão obtidos para os teores de umidade são baixos, o que auxilia a afirmar a redução de umidade equivalente entre as amostras, sob o mesmo binômio tempo/temperatura.

Figura 4 - Gráfico relação massa real de grãos versus tempo de secagem

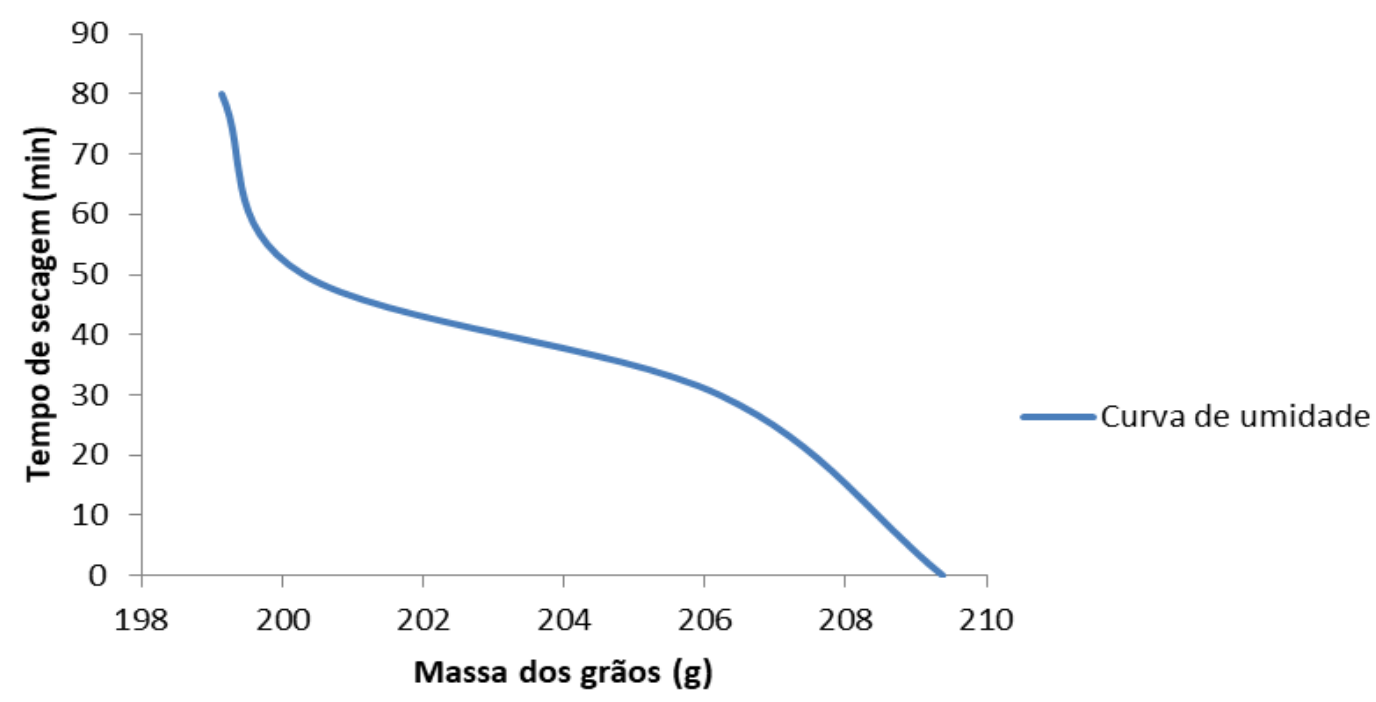

Fonte: Os autores 
Pode-se verificar também que a massa de grãos diminui no decorrer do período de secagem, onde a estrutura do grão mantém-se estável até 80 minutos da operação, tempo considerado então como o melhor para o processo.

Apesar das dificuldades encontradas para conclusão dos experimentos em tempo oportuno, foi possível compreender melhor a importância da etapa de armazenamento de alimentos, no presente estudo de grãos, no que se refere a garantir um produto de padrões de identidade e qualidade dentro das especificações regidas pela legislação, e portanto destacar a etapa de secagem como de fácil entendimento e realização, em curto período de tempo, garantindo um produto de melhor qualidade, com maior vida de prateleira.

O hardware necessário para conclusão dos experimentos está sendo concluído, e portanto, os resultados referentes aos objetivos especificados no plano de trabalho serão apresentados no SEMIC, caso sejam executados em tempo hábil para elaboração do material para apresentação.

\section{REFERÊNCIAS}

ANDRADE, E. T.; COUTO, A. M.; QUEIROZ, D. M.; PEIXOTO, A. B. Determinação de propriedades térmicas de grãos de milho. Ciência e Agrotecnologia, Lavras, v. 28, n. 3, p. 488-498, 2004.

BRASIL. Ministério da Agricultura e Reforma Agrária. Regras para análise de sementes. Brasília, DF, 365 p. 1992.

\section{EMPRESA BRASILEIRA DE PESQUISA AGROPECUÁRIA. Serviço de produção} de Informações. Recomendações técnicas para o cultivo do feijão; zonas 17 e 43. Brasília, 1993.

FAO. Food and Agriculture Organization of the United Nations. FAOSTAT. Disponível em: <http://faostat.fao.org/>. Acesso em: 9 Mar. 2017.

MAPA - MINISTÉRIO DA AGRICULTURA, PECUÁRIA E ABASTECIMENTO.

Conjuntura - $\quad 09 / 09 / 2010 \quad-\quad$ Feijão. Disponível em:

<http://www.agricultura.gov.br/arq_editor/file/camaras_setoriais/Feijao/15_reuniao/Consuo.p df $>$. 
MOREIRA, S. M. C.; CHAVES, M. A.; OLIVEIRA, L. M. Comparação da eficiência de líquidos na determinação da massa específica aparente de grãos agrícolas. Revista Brasileira de Armazenamento, Viçosa-MG, v.9/10, n.1/2, p.22-24, 1985.

RESENDE, O.; CORRÊA, P. C.; GONELI, A. L. D.; RIBEIRO, D. M. Propriedades físicas do feijão durante a secagem: determinação e modelagem. Ciência e Agrotecnologia, Lavras, v. 32, n. 1, p. 225-230, 2008.

SANTOS, M. M. Determinação das propriedades físicas, térmicas e aerodinâmicas do feijão carioca, cultivar estilo, em diferentes teores de água. TCC. Universidade Estadual de Goiás - UnUCET, Anápolis, 2014. 